\title{
Idiopathic Pulmonary Arterial
} Hypertension and Pulmonary Arterial Hypertension Associated With Congenital Heart Disease in Chinese Children: Similarities, Differences, and Prognostic Factors

\author{
Li Gu ${ }^{1,2}$, Yuan Yuan $L_{i}^{3}$, Ling $G u^{3}$, Liang $X i^{2}$ and Han Min Liu ${ }^{1,2 *}$
}

${ }^{1}$ Department of Pediatrics, West China Second University Hospital, Sichuan University, Chengdu, China, ${ }^{2}$ Key Laboratory of Birth Defects and Related Diseases of Women and Children (Sichuan University), Ministry of Education, West China Second University Hospital, Sichuan University, Chengdu, China, ${ }^{3}$ Laboratory of Pediatric Hematology/Oncology, West China Second University Hospital, Sichuan University, Chengdu, China

OPEN ACCESS

Edited by:

Laszlo Farkas,

The Ohio State University,

United States

Reviewed by:

Christian Apitz,

Ulm University Medical

Center, Germany

Yusei Ohshima,

University of Fukui, Japan

*Correspondence:

Han Min Liu

liuhm@scu.edu.cn

Specialty section:

This article was submitted to

Pediatric Pulmonology,

a section of the journal

Frontiers in Pediatrics

Received: 07 January 2020 Accepted: 02 March 2020

Published: 31 March 2020

Citation:

Gu L, Li YY, Gu L, Xie L and Liu HM (2020) Idiopathic Pulmonary Arterial Hypertension and Pulmonary Arterial

Hypertension Associated With

Congenital Heart Disease in Chinese Children: Similarities, Differences, and

Prognostic Factors.

Front. Pediatr. 8:106.

doi: 10.3389/fped.2020.00106
Background: As the most common types of pulmonary arterial hypertension (PAH) in childhood, the similarities and differences in clinical characteristics and prognosis between idiopathic PAH (IPAH) and PAH associated with congenital heart disease (PAH-CHD) are not well-known. This study describes and compares clinical features of pediatric IPAH and PAH-CHD in a single center of China during an 11-year period and explores the prognostic factors.

Methods: Twenty-five children with IPAH and 60 children with PAH-CHD, diagnosed in West China Second Hospital of Sichuan University from January 2008 to December 2018, were chosen as study objects. The follow-up deadline was June 2019, and the end-point was all-cause death. The baseline data, results of auxiliary examinations, treatment strategies, and follow-up outcomes were recorded and compared between IPAH and PAH-CHD patients to explore the similarities, differences, and prognostic factors.

Results: The median diagnostic age for $\mathrm{PAH}-\mathrm{CHD}$ patients was 2.3 years, which was younger than IPAH patients $(7.3$ years; $p=0.009)$. Sixty-eight percent of the IPAH patients presented with exercise-induced symptoms at initial diagnosis, whereas $58.3 \%$ of the PAH-CHD patients were asymptomatic $(p<0.001)$. Sixty percent of the IPAH patients were in World Health Organization-functional class (WHO-FC) III or IV, which was significantly worse than those of the PAH-CHD patients $(p=0.002)$. The incidence of ST-segment and T-wave (ST-T) change in children with IPAH (76.0\%) was significantly higher than that $(28.3 \%)$ in children with PAH-CHD ( $p<0.001)$. Mean corpuscular volume (MCV), mean platelet volume (MPV), and platelet distribution width were larger in IPAH patients than those in PAH-CHD patients $(p<0.01)$. The $1-$, 3-, and 5 -year survival rates of IPAH and PAH-CHD patients were 53.5, 46.5, and 31.2\% and 96.5, 93.1, and $77.6 \%$, respectively $(p<0.05)$. WHO-FC III-IV [relative risk $(\mathrm{RR})=2.750, p=0.008$ ] and higher MPV $(\mathrm{RR}=1.657, p=0.006)$ predicted poor prognosis for pediatric $\mathrm{PAH}$. 


\begin{abstract}
Conclusion: We showed that there are more differences than similarities between IPAH and PAH-CHD patients in clinical characteristics. PAH-CHD patients have a better prognosis than IPAH patients. WHO-FC III-IV and higher MPV at initial diagnosis are independent risk factors for poor prognosis.
\end{abstract}

Keywords: children, congenital heart disease, idiopathic, pulmonary arterial hypertension, prognosis

\section{INTRODUCTION}

Pulmonary arterial hypertension $(\mathrm{PAH})$ is a multifactorial and progressive disease, historically defined as a mean pulmonary artery pressure (mPAP) $\geq 25 \mathrm{mmHg}$ at rest measured by right heart catheterization (RHC) with a pulmonary artery wedge pressure (PAWP) $\leq 15 \mathrm{mmHg}$ and a pulmonary vascular resistance (PVR) $>3$ Wood units $(1,2)$. Recently, the 6th World Symposium on Pulmonary Hypertension has proposed to modify the definition for pulmonary hypertension as mPAP > $20 \mathrm{mmHg}$ in 2018 (3). Pulmonary vascular remodeling, resulting from vascular cells hypertrophy, hyperplasia, antiapoptosis, and accumulation of extracellular matrix in three layers (intima, media, and adventitia), is a hallmark of $\mathrm{PAH}(4,5)$. This structural change gradually results in increase in pulmonary artery pressure and PVR, which leads to elevation of right ventricular systolic pressure (RVSP), right ventricular hypertrophy, and eventually right heart failure and premature death $(1,2)$.

Registry studies all over the world indicate that idiopathic PAH (IPAH) and PAH associated with congenital heart disease (PAH-CHD) constitute the majority of cases in children (6). The true incidence and prevalence of pediatric IPAH and PAHCHD remain unknown but vary from country to country. An epidemiological study in Turkey has shown that the incidences of pediatric IPAH and secondary PAH including $\mathrm{PAH}-\mathrm{CHD}$ are 11.7 and 9.5 cases per million per year, respectively (7). However, the incidence of IPAH in children is only 0.48 case per million per year in a United Kingdom cohort study (8). From the data point of view, $\mathrm{PAH}$ is a rare disease in children. Unfortunately, the prognosis of the devastating disease remains poor, with 1-, 3-, and 5 -year survival rates of 89,85 , and $75 \%$, respectively $(8,9)$.

$\mathrm{PAH}$ is a significantly heterogeneous disease in terms of etiologies, and the management and prognosis are strongly correlated to the underlying causes, which emphasizes the importance of a correct diagnosis. Accurate diagnosis is based on a better understanding of pathogenesis. In fact, as the two most frequent causes of pediatric $\mathrm{PAH}$, little information of the similarities and differences between pediatric IPAH and PAHCHD has been known, although evidence has shown that there are more similarities than differences between PAH children and adults (10). Therefore, the aim of this study is to add data on potential differences between IPAH and PAH-CHD in children and to explore clinical indexes to reflect disease severity and predict prognosis.

\section{PATIENTS AND METHODS}

Twenty-five children with IPAH and 60 with PAH-CHD, who were diagnosed and treated in West China Second Hospital of
Sichuan University between January 2008 and December 2018, were included in this retrospective study. The obtained clinic data included baseline data of patients, results of lab tests, electrocardiogram results, hemodynamic parameters measured by transthoracic echocardiogram, and RHC and treatment strategies. All patients were followed up at $\sim 3$ monthly intervals. The follow-up deadline was June 2019, and the end-point was all-cause death. The study was approved by the institution ethics committee (approval number: 018).

\section{Statistical Analysis}

When continuous variables were normally distributed, the data were summarized as mean and SDs, whereas they were reported as median (interquartile range). Categorical data were described as frequency and percentage. Comparisons between groups were made using the independent Student's $t$-test, Wilcoxon rank sum test, Pearson chi-square, and Likelihood ratio test as appropriate. Correlations were tested using linear regression analysis. Kaplan-Meier survival curves were constructed for the determination of median survival. A comparison between survival curves was made by log rank test. Factors associated with prognosis were assessed using a Cox proportional hazards model. Statistical analysis was performed by SPSS 17.0 (SPSS, Chicago, United States). A $p<0.05$ was considered statistically significant.

\section{RESULTS}

\section{Demographics, Clinical Symptoms, and Signs}

The study population included $60 \mathrm{PAH}-\mathrm{CHD}$ patients and 25 IPAH patients. There were 52 female children, and the female/male ratio was 1.6:1. Ages at diagnosis ranged from 3 months to 14 years, and the median age was 3.3 years. Idiopathic $\mathrm{PAH}$ patients were older than PAH-CHD patients (7.3 vs. 2.3 years, $p=0.009$; Table 1 ).

In the IPAH group, three patients had a small patent ductus arteriosus (PDA) without significant hemodynamic changes, and one patient had a mild aortic stenosis. In PAH-CHD group, the types of associated CHD are listed in Table 1. From our data, we knew that $42(70.0 \%)$ patients had only one heart defect, and post-tricuspid shunt represented by PDA accounted for the majority among them. In addition, $26.7 \%$ patients had two or more defects. There was no Eisenmenger in our cohort.

Sixty-eight percent IPAH patients presented with exerciseinduced symptoms including dyspnea, chest pain, palpitation, and fatigue. Five children had syncope onset at the time of diagnosis, and all of them had IPAH. In contrast, 58.3\% PAH$\mathrm{CHD}$ patients were asymptomatic, and heart murmur was the 
TABLE 1 | Demographic characteristics and clinical presentation of PAH patients.

\begin{tabular}{|c|c|c|c|c|}
\hline Variables & All patients & PAH-CHD & IPAH & $P$-value \\
\hline Subjects & 85 & 60 & 25 & \\
\hline $\begin{array}{l}\text { Age at diagnosis } \\
\text { (years) }\end{array}$ & $3.3(1.0-8.7)$ & $2.3(0.7-8.4)$ & $7.3(1.9-12.5)$ & 0.009 \\
\hline $\begin{array}{l}\text { Female patients } n \\
(\%)\end{array}$ & $52(61.2)$ & $36(60.0)$ & $16(64.0)$ & 0.73 \\
\hline \multicolumn{5}{|c|}{ Clinical presentation } \\
\hline $\begin{array}{l}\text { Exercise-induced } \\
\text { symptoms } n(\%)\end{array}$ & 25 (29.4) & $8(13.3)$ & $17(68.0)$ & 0.000 \\
\hline $\begin{array}{l}\text { Peripheral edema } n \\
\text { (\%) }\end{array}$ & $6(7.1)$ & $3(5.0)$ & $3(12.0)$ & \\
\hline $\begin{array}{l}\text { Chronic cough } n \\
\text { (\%) }\end{array}$ & $5(5.9)$ & $4(6.7)$ & $1(4.0)$ & \\
\hline Syncope $n$ (\%) & $5(5.9)$ & $0(0)$ & $5(20.0)$ & \\
\hline $\begin{array}{l}\text { No. of symptoms } n \\
\text { (\%) }\end{array}$ & $36(42.4)$ & $35(58.3)$ & $1(4.0)$ & \\
\hline \multicolumn{5}{|l|}{ Clinical signs } \\
\hline $\begin{array}{l}\text { Accentuation of the } \\
\text { P2 } n(\%)\end{array}$ & $30(35.3)$ & 17 (28.3) & $13(52.0)$ & 0.001 \\
\hline $\begin{array}{l}\text { Cardiac murmur } n \\
(\%)\end{array}$ & $61(71.8)$ & $53(88.3)$ & $8(32.0)$ & \\
\hline $\begin{array}{l}\text { Right heart failure } \\
\text { signs } n(\%)\end{array}$ & $14(16.5)$ & $6(10.0)$ & $8(32.0)$ & \\
\hline No sign $n(\%)$ & $2(2.4)$ & $1(1.7)$ & $1(4.0)$ & \\
\hline $\begin{array}{l}\text { Congenital heart } \\
\text { defects }\end{array}$ & $63(74.1)$ & $60(100.0)$ & $3(12.0)$ & \\
\hline \multicolumn{5}{|l|}{ Pre-tricuspid shunt } \\
\hline ASD & $8(9.4)$ & $8(13.3)$ & 0 & \\
\hline $\begin{array}{l}\text { ASD+ pulmonary } \\
\text { stenosis }\end{array}$ & $2(2.4)$ & $2(3.3)$ & 0 & \\
\hline \multicolumn{5}{|c|}{ Post-tricuspid shunt } \\
\hline VSD & $5(5.9)$ & $5(8.3)$ & 0 & \\
\hline PDA & $23(27.1)$ & 20 (33.3) & $3(12.0)$ & \\
\hline VSD+PDA & $4(4.7)$ & $4(6.7)$ & 0 & \\
\hline $\begin{array}{l}\mathrm{PDA}+\text { pulmonary } \\
\text { stenosis }\end{array}$ & $3(3.5)$ & $3(5.0)$ & 0 & \\
\hline $\begin{array}{l}\text { VSD+ pulmonary } \\
\text { atresia }\end{array}$ & $2(2.4)$ & $2(3.3)$ & 0 & \\
\hline \multicolumn{5}{|c|}{ Both pre- and post-tricuspid shunt } \\
\hline ASD+PDA & $3(3.5)$ & $3(5.0)$ & 0 & \\
\hline VSD+ASD+PDA & $2(2.4)$ & $2(3.3)$ & 0 & \\
\hline \multicolumn{5}{|l|}{ Complex } \\
\hline $\begin{array}{l}\text { Complete } \\
\text { endocardial pad } \\
\text { defect }\end{array}$ & $1(1.2)$ & $1(1.7)$ & 0 & \\
\hline Tetralogy of Fallot & $1(1.2)$ & $1(1.7)$ & 0 & \\
\hline \multicolumn{5}{|c|}{ No. of systemic-to-pulmonary shunt } \\
\hline Pulmonary stenosis & $9(10.6)$ & $9(15.0)$ & 0 & \\
\hline \multicolumn{5}{|l|}{ WHO-FC } \\
\hline I-II n (\%) & $55(64.7)$ & $45(75.0)$ & $10(40.0)$ & 0.002 \\
\hline III-IV n (\%) & 30 (35.3) & 15 (25.0) & 15 (60.0) & \\
\hline
\end{tabular}

IPAH, idiopathic pulmonary arterial hypertension; $\mathrm{PAH}-\mathrm{CHD}$, pulmonary arterial hypertension associated with congenital heart disease; $P 2$, pulmonary component of the second heart sound; $A S D$, atrial septal defect; VSD, ventricular septal defect; PDA, patent ductus arteriosus; WHO-FC, World Health Organization functional class. major cause of admission ( $p<0.001$; Table 1). The most frequent physical signs of IPAH and $\mathrm{PAH}-\mathrm{CHD}$ patients were enhancement of the second heart sound and heart murmur, respectively ( $p=0.001$; Table 1 ). Fifteen (60.0\%) IPAH patients presented with World Health Organization-functional class (WHO-FC) III or IV at initial diagnosis, which was worse than PAH-CHD patients ( $p=0.002$; Table 1$)$.

\section{Laboratory Tests, Image Examination, and Hemodynamic Characteristics}

Blood routine test showed that mean corpuscular volume (MCV), mean platelet volume (MPV), and platelet distribution width (PDW) of IPAH patients were larger than those of PAH-CHD patients ( $p<0.01$; Table 2$)$.

The results of electrocardiogram test for both pediatric IPAH and PAH-CHD patients showed that right ventricular hypertrophy (72.9\%), ST-segment and T-wave (ST-T) change (42.4\%), and arrhythmia (20.0\%) were the major changes (Table 2). Nineteen (76.0\%) patients with IPAH had ST-T change, which was significantly higher than that $(28.3 \%)$ of PAH-CHD patients $(p<0.001$; Table 2$)$. In addition, complete or incomplete right bundle branch block (RBBB) was the most common type of arrhythmia in PAH-CHD patients. Meanwhile, RBBB was also found in IPAH patients, but there was no dominant arrhythmia type in this group ( $p>0.05$; Table 2 ).

All children had echocardiograph test, and tricuspid regurgitation (TR) was present in 50\% $\mathrm{PAH}-\mathrm{CHD}$ patients and in $100 \%$ IPAH patients. Sixty-eight patients (85.0\%) underwent initial RHC. Although all hemodynamic parameters were dramatically elevated, there was no statistical difference between IPAH patients and PAH-CHD patients for these parameters $(p>$ 0.05; Table 2).

\section{Treatment and Survival}

In this study, nine PAH-CHD and four IPAH patients were lost to follow-up due to various reasons. There were 51 available PAHCHD cases including 48 patients with pre-operative $\mathrm{PAH}$ and 3 patients diagnosed as PAH after cardiac repair surgery. More detailly, among the three post-operative PAH-CHD cases, two were diagnosed as PAH 5 or 7 years after receiving transcatheter closure for ventricular septal defect (VSD), respectively, and bosentan and sildenafil were prescribed to them for treatment. Another case was a 2-year-old boy, who was diagnosed as having PAH 6 months after receiving surgery for tetralogy of Fallot, and finally died of heart failure 3 days after diagnosis. Of the 48 cases with preoperative $\mathrm{PAH}-\mathrm{CHD}$, half were persistent $\mathrm{PAH}$, and half were clarified to transient PAH, because the level of PAP could decrease to normal after transcatheter closure. Treatments were given to the 24 persistent PAH-CHD cases subsequently, of which five received cardiac repair surgery plus bosentan, six underwent heart surgery only, and seven took bosentan orally only. Among the 21 IPAH cases, only 12 (57\%) patients were treated with endothelin receptor antagonist represented by bosentan. Three of six PAH-CHD patients without surgery and PAH-targeted drugs and five of nine IPAH patients without PAH-targeted drugs preferred to choose intermittent treatment with traditional Chinese medicine. 
TABLE 2 | Laboratory tests, electrocardiogram results, and hemodynamic characteristics of $\mathrm{PAH}$ patients.

\begin{tabular}{|c|c|c|c|c|}
\hline Variables & All patients & PAH-CHD & IPAH & $P$-value \\
\hline Subjects & 85 & 60 & 25 & \\
\hline \multicolumn{5}{|l|}{ Blood routine test } \\
\hline Baseline & $n=83$ & $n=60$ & $n=23$ & \\
\hline $\operatorname{MCV}(f l)$ & $78.6 \pm 8.7$ & $76.8 \pm 8.5$ & $83.2 \pm 7.5$ & 0.002 \\
\hline RDW(\%) & $\begin{array}{c}14.6 \\
(13.5-15.8)\end{array}$ & $\begin{array}{c}14.7 \\
(13.4-16.0)\end{array}$ & $\begin{array}{c}14.6 \\
(13.7-15.7)\end{array}$ & 0.839 \\
\hline MPV(fl) & $10.2 \pm 1.3$ & $9.8 \pm 1.1$ & $11.1 \pm 1.4$ & 0.000 \\
\hline PDW(\%) & $11.7 \pm 2.3$ & $11.1 \pm 2.0$ & $13.5 \pm 2.4$ & 0.000 \\
\hline \multicolumn{5}{|c|}{ Electrocardiogram test } \\
\hline Baseline & $n=85$ & $n=60$ & $n=25$ & \\
\hline $\begin{array}{l}\text { Right ventricular } \\
\text { hypertrophy }\end{array}$ & $62(72.9)$ & $41(68.3)$ & $21(84.0)$ & 0.139 \\
\hline ST-T change & $36(42.4)$ & $17(28.3)$ & 19 (76.0) & 0.000 \\
\hline Arrhythmia & $17(20.0)$ & $12(20.0)$ & $5(20.0)$ & \\
\hline $\begin{array}{l}\text { Right bundle } \\
\text { branch block }\end{array}$ & $7(8.2)$ & $6(10.0)$ & $1(4.0)$ & 0.329 \\
\hline Sinus tachycardia & $3(3.5)$ & $3(5.0)$ & 0 & 0.144 \\
\hline Sinus bradycardia & $1(1.2)$ & 0 & $1(4.0)$ & 0.116 \\
\hline Sinus arrhythmia & $3(3.5)$ & $1(1.7)$ & $2(8.0)$ & 0.174 \\
\hline $\begin{array}{l}\text { Premature atrial } \\
\text { contractions }\end{array}$ & $2(2.4)$ & $1(1.7)$ & $1(4.0)$ & 0.537 \\
\hline $\begin{array}{l}\text { Preexcitation } \\
\text { syndrome }\end{array}$ & $1(1.2)$ & 0 & $1(4.0)$ & 0.116 \\
\hline \multicolumn{5}{|c|}{ Echocardiography test } \\
\hline $\begin{array}{l}\text { Numbers of } \\
\text { patients with TR }\end{array}$ & $n=55$ & $n=30$ & $n=25$ & \\
\hline SPAP (mmHg) & $74.0 \pm 25.1$ & $72.9 \pm 24.6$ & $75.4 \pm 26.2$ & 0.714 \\
\hline $\operatorname{Vmax}(\mathrm{m} / \mathrm{s})$ & $3.9 \pm 0.7$ & $3.9 \pm 0.7$ & $4.0 \pm 0.7$ & 0.762 \\
\hline $\begin{array}{l}\text { Diameter of PA } \\
(\mathrm{mm})\end{array}$ & $23.7 \pm 5.9$ & $23.1 \pm 6.6$ & $24.1 \pm 5.3$ & 0.585 \\
\hline \multicolumn{5}{|l|}{ Hemodynamics } \\
\hline Baseline & $n=68$ & $n=54$ & $n=14$ & \\
\hline SPAP (mmHg) & $78.3 \pm 27.3$ & $76.3 \pm 28.3$ & $85.9 \pm 22.6$ & 0.248 \\
\hline DPAP (mmHg) & $39.9 \pm 22.7$ & $38.5 \pm 24.0$ & $45.0 \pm 16.3$ & 0.243 \\
\hline mPAP (mmHg) & $55.5 \pm 22.4$ & $55.1 \pm 23.9$ & $57.4 \pm 16.5$ & 0.677 \\
\hline RVSP (mmHg) & $82.2 \pm 28.1$ & $81.3 \pm 29.9$ & $85.8 \pm 20.5$ & 0.516 \\
\hline mRVP (mmHg) & $38.9 \pm 14.2$ & $40.4 \pm 14.8$ & $33.2 \pm 10.4$ & 0.094 \\
\hline PVRI (WU'm²) & $20.3 \pm 9.6$ & $20.1 \pm 10.1$ & $20.7 \pm 9.1$ & 0.845 \\
\hline
\end{tabular}

IPAH, idiopathic pulmonary arterial hypertension; $P A H-C H D$, pulmonary arterial hypertension associated with congenital heart disease; $\mathrm{MCV}$, mean corpuscular volume; $R D W$, red blood cell distribution width; MPV, mean platelet volume; PDW, platelet distribution width; TR, tricuspid regurgitation; SPAP, systolic pulmonary artery pressure; DPAP, diastolic pulmonary artery pressure; MPAP, mean pulmonary artery pressure; RVSP, right ventricular systolic pressure; mRVP, mean right ventricular pressure; $P V R I$, pulmonary vascular resistance index; and Vmax, maximal systolic tricuspid regurgitant velocity.

Follow-up of 72 patients from the time of diagnosis ranged from 1 to 113 months (median, 19 months). Median survival for all patients was 89 months, with 1-, 3-, and 5-year survival rates of $84,79.6$, and $62 \%$, respectively (Figure 1). Overall, survival for PAH-CHD patients was better than IPAH patients (median survival, 89 vs. 18 months; 1-, 3-, 5-year survival rates, 96.5, 93.1, $77.6 \%$ vs. $53.5,46.8$, and $31.2 \%, p<0.001$; Figure 2 ).

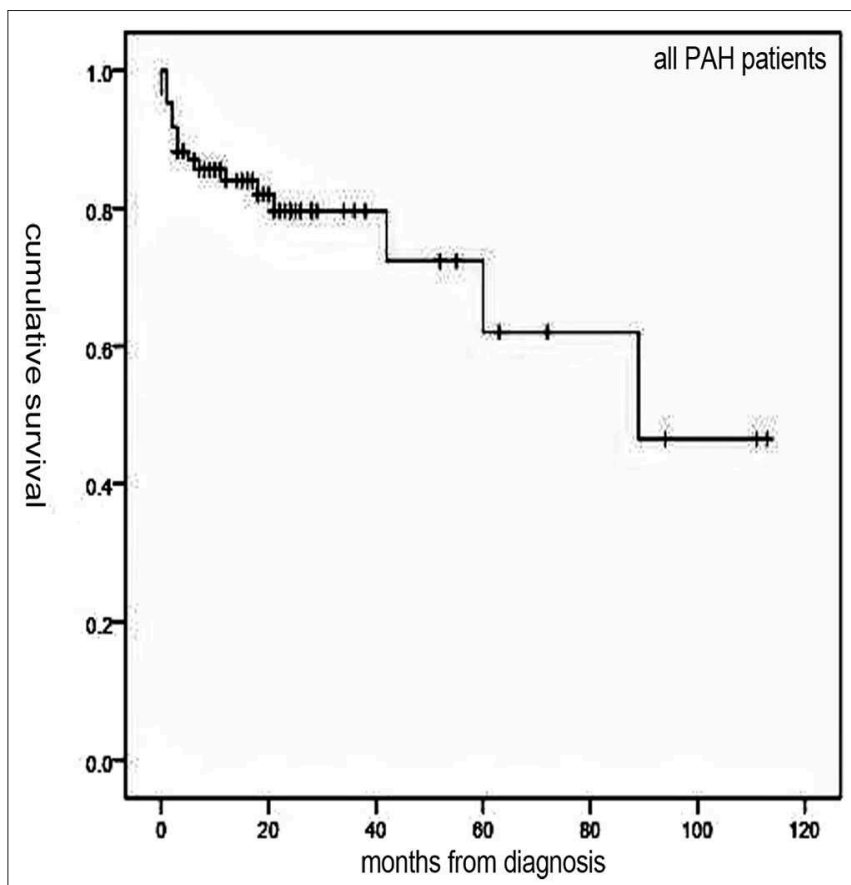

FIGURE 1 | The Kaplan-Meier curve of all pulmonary arterial hypertension $(\mathrm{PAH})$ patients.

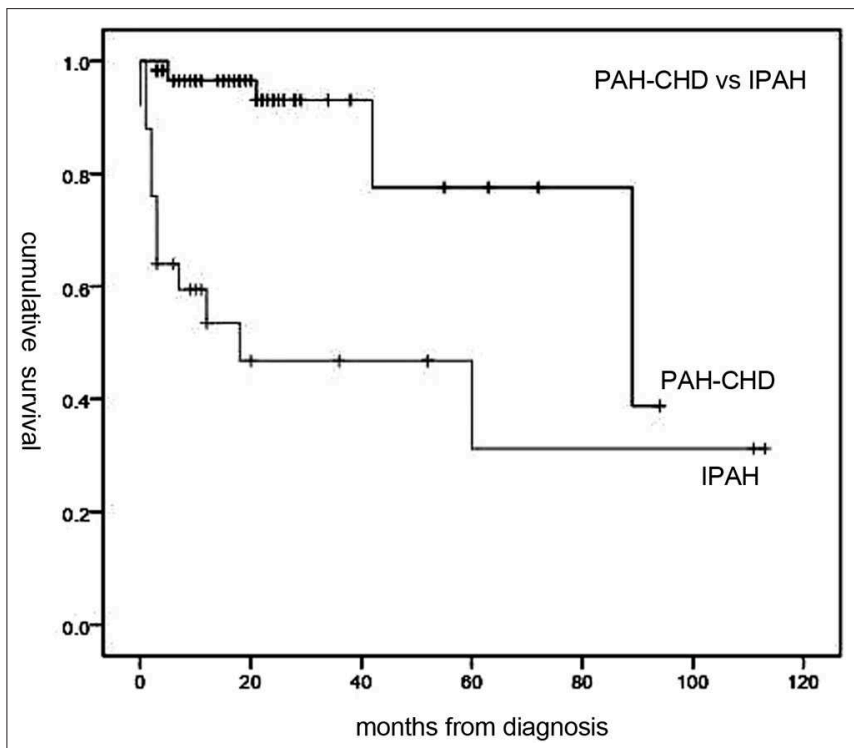

FIGURE 2 | Median survival time of idiopathic pulmonary arterial hypertension $(\mathrm{IPAH})$ and $\mathrm{PAH}$ associated with congenital heart disease (PAH-CHD) patients. Patients with $\mathrm{PAH}-\mathrm{CHD}$ showed significantly better survival than those with IPAH $(p<0.001)$.

\section{Prognostic Factors}

In addition to 13 patients with lost visit and 24 patients with transient $\mathrm{PAH}-\mathrm{CHD}$, the remaining 48 patients were divided into non-survival group $(n=18)$ and survival group $(n=30)$ to explore the prognostic factors. Univariable analysis found 
TABLE 3 | Univariate analysis of pediatric PAH prognosis.

\begin{tabular}{|c|c|c|c|}
\hline Variables & Non-survival & Survival & $P$-value \\
\hline Subjects & 18 & 30 & \\
\hline $\begin{array}{l}\text { Age at diagnosis } \\
\text { (years) }\end{array}$ & $6.8 \pm 5.5$ & $5.5 \pm 4.1$ & 0.376 \\
\hline $\begin{array}{l}\text { Female patients } n \\
\text { (\%) }\end{array}$ & $12(66.7)$ & $18(60.0)$ & 0.644 \\
\hline \multicolumn{4}{|c|}{ Clinical presentation } \\
\hline $\begin{array}{l}\text { Exercise-induced } \\
\text { symptoms } n(\%)\end{array}$ & $11(60.1)$ & $10(33.3)$ & 0.06 \\
\hline Cyanosis $n(\%)$ & $4(22.2)$ & $2(6.7)$ & 0.121 \\
\hline Syncope $n(\%)$ & $4(22.2)$ & $1(3.3)$ & 0.039 \\
\hline $\begin{array}{l}\text { Right heart failure } \\
\text { signs } n(\%)\end{array}$ & $7(38.9)$ & $5(16.7)$ & 0.085 \\
\hline IPAH counts $n(\%)$ & $13(72.2)$ & $8(26.7)$ & 0.002 \\
\hline \multicolumn{4}{|l|}{ WHO-FC } \\
\hline |-|| n (\%) & $3(16.7)$ & $17(56.7)$ & 0.007 \\
\hline III-IV n (\%) & 15 (83.3) & $13(43.3)$ & \\
\hline \multicolumn{4}{|l|}{ Blood routine test } \\
\hline Baseline & $n=17$ & $n=30$ & \\
\hline MCV (fl) & $83.8 \pm 10.0$ & $77.1 \pm 7.9$ & 0.015 \\
\hline RDW (\%) & $\begin{array}{c}15.1 \\
(14.1-16.5)\end{array}$ & $\begin{array}{c}15.2 \\
(13.9-17.6)\end{array}$ & 0.921 \\
\hline MPV (fl) & $11.7 \pm 1.5$ & $10.0 \pm 0.9$ & 0.000 \\
\hline PDW (\%) & $14.3 \pm 2.5$ & $11.4 \pm 1.7$ & 0.000 \\
\hline \multicolumn{4}{|l|}{ Hemodynamics } \\
\hline Baseline & $n=9$ & $n=26$ & \\
\hline SPAP (mmHg) & $94.7 \pm 14.8$ & $90.5 \pm 26.4$ & 0.658 \\
\hline DPAP (mmHg) & $48.3 \pm 24.1$ & $48.0 \pm 24.3$ & 0.972 \\
\hline mPAP (mmHg) & $61.4 \pm 19.9$ & $66.2 \pm 23.5$ & 0.594 \\
\hline RVSP (mmHg) & $94.8 \pm 13.9$ & $91.8 \pm 28.8$ & 0.772 \\
\hline mRVP (mmHg) & $39.0 \pm 13$ & $43.0 \pm 16.5$ & 0.515 \\
\hline PVRI (Wood Units) & $22.0 \pm 7.9$ & $20.8 \pm 10.1$ & 0.758 \\
\hline
\end{tabular}

WHO-FC, World Health Organization functional class; IPAH, idiopathic pulmonary arterial hypertension; MCV, mean corpuscular volume; RDW, red blood cell distribution width; MPV, mean platelet volume; PDW, platelet distribution width; SPAP, systolic pulmonary artery pressure; DPAP, diastolic pulmonary artery pressure; MPAP, mean pulmonary artery pressure; RVSP, right ventricular systolic pressure; $m R V P$, mean right ventricular pressure; and PVRI, pulmonary vascular resistance index.

six indexes were significantly different ( $p<0.05$; Table 3). Cox proportional hazards model was further conducted, and the results revealed IPAH [hazard ratio $(\mathrm{HR})=3.176, p=0.035$ ], WHO-FC III-IV $(\mathrm{HR}=2.750, p=0.008)$ and higher MPV $(\mathrm{HR}=1.657, p=0.006)$ were predictors for poor prognosis (Table 4). However, there was no correlation between MPV and hemodynamic parameters.

\section{DISCUSSION}

This study describes and compares the clinical features of pediatric IPAH and PAH-CHD, derived from southwest China data involving a 11-year period. Similar to other reports $(8,11)$, we find that both IPAH and PAH-CHD are female-dominated vasculopathy with a female/male
TABLE 4 | Multivariate Cox regression analyses of predictors of mortality in patients with $\mathrm{PAH}$.

\begin{tabular}{lccc}
\hline Variables & Hazard ratio & 95\% confidence interval & $\boldsymbol{P}$-value \\
\hline IPAH vs. PAH-CHD & 3.176 & $1.088-9.275$ & 0.035 \\
WHO-FC (III, IV vs. I, II) & 2.75 & $1.308-5.781$ & 0.008 \\
MPV & 1.657 & $1.160-2.369$ & 0.006 \\
\hline
\end{tabular}

IPAH, idiopathic pulmonary arterial hypertension; $\mathrm{PAH}-\mathrm{CHD}$, pulmonary arterial hypertension associated with congenital heart disease; WHO-FC, World Health Organization functional class; MPV, mean platelet volume.

ratio of $1.6: 1$, and there is no difference in hemodynamic parameters, suggesting that they only contribute to the diagnosis of PAH and could not distinguish the etiology. However, in terms of diagnostic age, clinical manifestations, results of lab tests, and prognosis, we first show that there are more differences than similarities between IPAH and $\mathrm{PAH}-\mathrm{CHD}$ in children. In addition to WHO-FC, an already known predictor for PAH (12), we also find that MPV is a valuable prognosis-associated factor. We believe that those differences in clinical features and new prognostic factors are helpful for physicians to better understand and diagnose pediatric IPAH and PAH-CHD and to guide medical management.

The 2015 European Society of Cardiology (ESC)/European Respiratory Society (ERS) guideline defines syncope as a risk factor for poor prognosis in adults with PAH (2), but the prognostic significance have not been demonstrated in pediatric $\mathrm{PAH}$ and remains controversial. In this study, five IPAH patients have syncope onset, and the incidence of $20 \%$ is lower than that in a pediatric PAH registry [31\%; (13)] but slightly higher than that in adults 12\%; (14). The age ranges from 4.2 to 14 years with an average age of 9.9 years, indicating that syncope occurs mainly in older children. Although univariate analysis shows a higher composition of syncope in non-survival patients, further multivariate analysis shows that there is no correlation between syncope and poor outcome, which is consistent with another retrospective study (15). Regarding the value of syncope, high-quality researches are urgently needed.

In this study, we find that MCV, MPV, and PDW are higher in IPAH and non-survival group than those in PAH-CHD and survival group, respectively, but RDW has no difference. MCV and RDW are two useful parameters, reflecting the volume of red blood cell and the degree of heterogeneity of erythrocyte size, respectively. Previously, RDW has been regarded as an independent prognostic indicator in adult with $\mathrm{PAH}(16,17)$ as well as Eisenmenger syndrome (18). However, the prognostic value is not confirmed in pediatric PAH (19). Similarly, we have not demonstrated that MCV and RDW could predict the PAH prognosis in children. MPV and PDW, markers of platelet activation, are larger in non-survivals in our study, which is consistent with the study of Mese et al. (20), but multivariate analysis shows that only MPV is a prognostic factor for PAH. The prevailing view is that larger platelets are more active metabolically and enzymatically in comparison to smaller ones. In terms of pathological mechanism, activated 
platelets are involved in the formation of in situ thrombosis, which is an obvious pathological characteristics of PAH and might be related to pulmonary vascular endothelia dysfunction, systemic inflammation, and immune dysfunction (21, 22). Therefore, from this perspective, we can explain that larger MPV means larger platelets and stronger ability to promote thrombosis, and from the theoretical point of view, the quantity of thrombus should be positively correlated with the disease severity and prognosis.

From our data, we know the prognosis of pediatric $\mathrm{PAH}-$ CHD is significantly better than that of IPAH. After removal of temporary PAH-CHD cases, the 1-, 3-, 5-year survival rates of persistent $\mathrm{PAH}-\mathrm{CHD}$ patients remain as high as 92.6, 86.8, and $69.4 \%$, respectively, and the reasons are multifactional. On the one hand, the existence of $\mathrm{CHD}$ requires these children to seek regular medical consultations, which breaks the symptomdriven mode of seeking medical treatment in China, and which contributes to the early detection of PAH-CHD. Thus, although $58.3 \% \mathrm{PAH}-\mathrm{CHD}$ patients are asymptomatic at initial diagnosis, the median diagnostic age is as young as 2.3 years, and most of them are presented with WHO-FC I-II. In contrast, $68 \%$ patients with IPAH have already exhibited non-negligible symptoms of exercise limitation including dyspnea, fatigue, and chest pain at the first time of diagnosis, so the majority of them have poor heart function, presenting with WHO-FC III-IV. In addition to a delayed diagnosis, this is also related to the rapid progression of IPAH (23). On the other hand, successful cardiac repair surgery can also improve the survival rate of patients with CHD. Our research shows that half of the children with preoperative $\mathrm{PAH}-\mathrm{CHD}$ recover to normal after transcatheter closure. Unfortunately, only $57 \%$ children with IPAH receive one $\mathrm{PAH}$-targeted drug represented by bosentan, and there is no case of combination therapy. Many factors with regional and temporal feature such as family economics, health insurance policies, parental acceptances, doctors' experiences, and availability of drugs influence the final decision of treatment strategies.

Our study has some limitations. First, it is a retrospective study with a small sample size in a single center. Second, all observation indicators are only recorded at initial diagnosis, and the dynamic changes during the process of follow-up are unknown. Finally, the correlation between MPV and some repeatedly confirmed prognostic factors such as serum $\mathrm{N}$-terminal pro b-type natriuretic peptide (NT-proBNP) and uric acid for pediatric PAH is not analyzed; therefore, the prognostic value of MPV may not be universally applicable.

\section{REFERENCES}

1. Hoeper MM, Bogaard HJ, Condliffe R, Frantz R, Khanna D, Kurzyna M, et al. Definitions and diagnosis of pulmonary hypertension. J Am Coll Cardiol. (2013) 62(25 Suppl):D42-50. doi: 10.1016/j.jacc.2013.10.032

2. Galie N, Humbert M, Vachiery JL, Gibbs S, Lang I, Torbicki A, et al. 2015 ESC/ERS guidelines for the diagnosis and treatment of pulmonary hypertension: the joint task force for the diagnosis and treatment of pulmonary hypertension of the European Society of Cardiology (ESC) and the
In conclusion, there are more differences than similarities between pediatric IPAH and $\mathrm{PAH}-\mathrm{CHD}$ in clinical characteristics, and differences are shown as follows: (i) The diagnostic age of IPAH patients is older than PAH-CHD patients; (ii) $68 \%$ IPAH patients present with exercise-induced symptoms, but $58.3 \%$ PAH-CHD patients are asymptomatic at the time of diagnosis; (iii) the incidence of ST-T change in IPAH is higher than that in PAH-CHD; (iv) WHO-FC III-IV is presented in $60 \%$ IPAH patients, which is higher than in PAH-CHD patients (25\%); (v) IPAH patients have a larger values of MCV, MPV, and PDW than PAH-CHD patients; and (vi) the prognosis of PAH-CHD patients is better than that of IPAH patients. As for the prognostic factors, we show that WHO-FC III-IV and higher MPV at the time of diagnosis are independent predictors of poor prognosis for pediatric PAH.

\section{DATA AVAILABILITY STATEMENT}

The datasets generated for this study are available on request to the corresponding author.

\section{ETHICS STATEMENT}

The studies involving human participants were reviewed and approved by Ethics Committee of West China Second Hospital of Sichuan University. Written informed consent to participate in this study was provided by the participants' legal guardian/next of kin.

\section{AUTHOR CONTRIBUTIONS}

LiG: data collection, management and analysis, manuscript drafting and revision. YL: data collection and manuscript revision. LinG and LX: site oversight and manuscript revision. ML: study concept and design, interpretation of results, manuscript revision, and final approval.

\section{FUNDING}

This work was supported by the National Natural Science Foundation of China (No. 81670280).

\section{ACKNOWLEDGMENTS}

We thank Profs. Fan Hu and Li Yu for their convenience and help in applying for access to case data of children with PAH.

European Respiratory Society (ERS): endorsed by: Association for European Paediatric and Congenital Cardiology (AEPC), International Society for Heart and Lung Transplantation (ISHLT). Eur Heart J. (2016) 37:67-119. doi: 10.1093/eurheartj/ehv317

3. Rosenzweig EB, Abman SH, Adatia I, Beghetti M, Bonnet D, Haworth S, et al. Paediatric pulmonary arterial hypertension: updates on definition, classification, diagnostics and management. Eur Respir J. (2019) 53:1801916. doi: 10.1183/13993003.0191 6-2018 
4. Tuder RM, Marecki JC, Richter A, Fijalkowska I, Flores S. Pathology of pulmonary hypertension. Clin Chest Med. (2007) 28:23-42. doi: 10.1016/j.ccm.2006.11.010

5. Guignabert C, Tu L, Le Hiress M, Ricard N, Sattler C, Seferian A, et al. Pathogenesis of pulmonary arterial hypertension: lessons from cancer. Eur Respir Rev. (2013) 22:543-51. doi: 10.1183/09059180.00007513

6. van Loon RLE, Roofthooft MTR, Hillege HL, ten Harkel ADJ, van Osch-Gevers $M$, Delhaas $T$, et al. Pediatric pulmonary hypertension in the Netherlands epidemiology and characterization during the period 1991 to 2005. Circulation. (2011) 124:1755-64. doi: 10.1161/circulationaha.110.969584

7. Pektas A, Pektas BM, Kula S. An epidemiological study of paediatric pulmonary hypertension in Turkey. Cardiol Young. (2016) 26:693-7. doi: $10.1017 /$ S1047951115001043

8. Moledina S, Hislop AA, Foster H, Schulze-Neick I, Haworth SG. Childhood idiopathic pulmonary arterial hypertension: a national cohort study. Heart. (2010) 96:1401-6. doi: 10.1136/hrt.2009.182378

9. del Cerro Marin MJ, Sabate Rotes A, Rodriguez Ogando A, Mendoza Soto A, Quero Jimenez M, Gavilan Camacho JL, et al. Assessing pulmonary hypertensive vascular disease in childhood. Data from the Spanish registry. Am J Respir Crit Care Med. (2014) 190:1421-9. doi: 10.1164/rccm.201406-1052OC

10. Barst RJ, Ertel SI, Beghetti M, Ivy DD. Pulmonary arterial hypertension: a comparison between children and adults. Eur Respir J. (2011) 37:665-77. doi: 10.1183/09031936.00056110

11. Widlitz A, Barst RJ. Pulmonary arterial hypertension in children. Eur Respir J. (2003) 21:155-76. doi: 10.1183/09031936.03.00088302

12. Kula S, Canbeyli F, Atasayan V, Tunaoglu FS, Oguz AD. A retrospective study on children with pulmonary arterial hypertension: a single-center experience. Anatol J Cardiol. (2018) 20:41-7. doi: 10.14744/AnatolJCardiol.2018.78370

13. Berger RMF, Beghetti M, Humpl T, Raskob GE, Ivy DD, Jing Z-C, et al. Clinical features of paediatric pulmonary hypertension: a registry study. Lancet. (2012) 379:537-46. doi: 10.1016/s0140-6736(11)61621-8

14. Le RJ, Fenstad ER, Maradit-Kremers H, McCully RB, Frantz RP, McGoon $\mathrm{MD}$, et al. Syncope in adults with pulmonary arterial hypertension. J Am Coll Cardiol. (2011) 58:863-7. doi: 10.1016/j.jacc.2011.04.026

15. Takatsuki S, Yanai S, Ikehara S, Nakayama T, Matsuura H. Clinical effects of syncope on disease severity and adverse outcomes in children with idiopathic and heritable pulmonary arterial hypertension. Pediatr Cardiol. (2019) 40:209-214. doi: 10.1007/s00246-018-1996-3

16. Rhodes CJ, Wharton J, Howard LS, Gibbs JS, Wilkins MR. Red cell distribution width outperforms other potential circulating biomarkers in predicting survival in idiopathic pulmonary arterial hypertension. Heart.
(2011) 97:1054-60. doi: 10.1136/hrt.2011.224857

17. Smukowska-Gorynia A, Tomaszewska I, Malaczynska-Rajpold K, Marcinkowska J, Komosa A, Janus M, et al. Red blood cells distribution width as a potential prognostic biomarker in patients with pulmonary arterial hypertension and chronic thromboembolic pulmonary hypertension. Heart Lung Circ. (2018) 27:842-8. doi: 10.1016/j.hlc.2017.08.007

18. Yang T, Sun YJ, Xiong CM, Zeng WJ, Ni XH, Zhao ZH, et al. Red blood cell distribution width predicts survival in patients with Eisenmenger syndrome. Clin Chem Lab Med. (2014) 52:743-50. doi: 10.1515/cclm2013-0747

19. Zuk M, Migdal A, Dominczak J, Brzezinska-Rajszys G. Usefulness of Red Cell Width Distribution (RDW) in the assessment of children with Pulmonary Arterial Hypertension (PAH). Pediatr Cardiol. (2019) 40:820-826. doi: 10.1007/s00246-019-0 2077-4

20. Mese T, Guven B, Yilmazer MM, Karadeniz C, Ozdemir R, Doksoz O. Platelet activation markers in children with congenital heart disease associated with pulmonary arterial hypertension. Congenit Heart Dis. (2018) 13:506-11. doi: $10.1111 /$ chd.12616

21. Huertas A, Perros F, Tu L, Cohen-Kaminsky S, Montani D, Dorfmuller $P$, et al. Immune dysregulation and endothelial dysfunction in pulmonary arterial hypertension: a complex interplay. Circulation. (2014) 129:1332-40. doi: 10.1161/circulationaha.113.0 04555

22. Rabinovitch M, Guignabert C, Humbert M, Nicolls MR. Inflammation and immunity in the pathogenesis of pulmonary arterial hypertension. Circ Res. (2014) 115:165-75. doi: 10.1161/circresaha.113.3 01141

23. Chung WJ, Park YB, Jeon CH, Jung JW, Ko KP, Choi SJ, et al. Baseline characteristics of the Korean registry of pulmonary arterial hypertension. J Korean Med Sci. (2015) 30:1429-38. doi: 10.3346/jkms.2015.30. 10.1429

Conflict of Interest: The authors declare that the research was conducted in the absence of any commercial or financial relationships that could be construed as a potential conflict of interest.

Copyright (c) $2020 \mathrm{Gu}, \mathrm{Li}, \mathrm{Gu}$, Xie and Liu. This is an open-access article distributed under the terms of the Creative Commons Attribution License (CC BY). The use, distribution or reproduction in other forums is permitted, provided the original author(s) and the copyright owner(s) are credited and that the original publication in this journal is cited, in accordance with accepted academic practice. No use, distribution or reproduction is permitted which does not comply with these terms. 